\title{
Prevalence of allergy in children with adenoid hypertrophy and otitis media with effusion admitted to the Department of Pediatric Otolaryngology in Poznan
}

\author{
PAULINA ADAMCZYK ${ }^{A, B}, \mathrm{D}, \mathrm{E}, \mathrm{F}, \mathrm{BEATA}$ PUCHER ${ }^{\mathrm{A}, \mathrm{B}, \mathrm{E}}, \mathrm{MAGDALENA} \mathrm{PRAUZIŃSKA}^{\mathrm{B}}$, \\ AGATA KA $Ł U Z ̇ N A-M Ł Y N A R C Z Y K^{A, B}$, MICHAŁ KOTOWSKIB, JAROSŁAW SZYDŁOWSKIA, D, E
}

Pediatric Otolaryngology Department, Poznan University of Medical Sciences, Poland

A - Study Design, B - Data Collection, C - Statistical Analysis, D - Data Interpretation, E - Manuscript Preparation, F - Literature Search, $\mathbf{G}$ - Funds Collection

Summary Background. Allergic diseases are the most common chronic illnesses in children. It is said that patients with allergy more often suffer from adenoid hypertrophy and otitis media with effusion than non-allergic patients.

Objectives. To estabilish the prevalence of allergy in children with adenoid hypertrophy with or without otitis media with effusion (OME) admitted to the Department of Pediatric Otolaryngology in Poznan between 05.2017 and 05.2018 and to check if allergy affects the incidence of OME and adenoid hypertrophy.

Material and methods. Each patient admitted for adenoidecomy or tympanostomy tube placement or both was carefully interviewed to check if they suffered from allergic diseases. In every patient with OME, a preoperative tympanometry and pure tone audiogram or otoacoustic emission was performed. The data was analyzed statistically. The chi-square test was used, with a $p$ value $<0.05$.

Results. 153 patients aged 2 to 16 years ( 68 girls and 85 boys) were admitted to the Poznan Pediatric Otolaryngology Department between 05.2017 and 05.2018 . The children were divided in to three age subgroups. $16.9 \%$ of children undergoing adenoidectomy and $17.4 \%$ of children undergoing adenoidectomy with tympanostomy tube placement suffered from allergic disease. Allergy did not affect the incidence of OME or adenoid hypertrophy, but this finding was not statistically significant. OME diagnosis and ear tube placement was statistically more often seen in boys $\left(p=0.02\right.$, chi $\left.^{2}=5.39\right)$.

Conclusions. Prevalence of allergy was higher in boys and they had more often ear tubes placement performed. That difference was statistically significant. Allergy in our study group did not influence the prevalence of OME, nor the adenoid hypertrophy. Key words: hypersensitivity, adenoids, otitis media with effusion.

Adamczyk P, Pucher B, Prauzińska M, Kałużna-Młynarczyk A, Kotowski M, Szydłowski J. Prevalence of allergy in children with adenoid hypertrophy and otitis media with effusion admitted to the Department of Pediatric Otolaryngology in Poznan. Fam Med Prim Care Rev 2018; 20(3): 205-209, doi: https://doi.org/10.5114/fmpcr.2018.78252.

\section{Background}

Allergic diseases are the most common chronic condition in children in Poland. It is said that $11 \%$ of children and $17 \%$ of adolescents in the Polish population suffer from allergy [1]. It is estimated that children with allergy are more susceptible to either acute otitis media (AOM) or otitis media with effusion (OME) [2]. There are various factors contributing to this. Firstly, the Eustachian tube, the structure responsible for equalizing middle ear pressure, might become mechanically blocked by enlarged adenoid or swollen nasal mucosa. Such an obstruction may result in poor ear ventilation. In patients with allergic rhinitis (AR), the nasal mucosa is swollen, causing Eustachian tube dysfunction, which eventually leads to otitis media with effusion [2]. Adenoid hypertrophy may also cause Eustachian tube blockage and subsequently lead to the same condition. According to literature, children with allergic diseases more often suffer from adenoid hypertrophy than other children [3].

Another explanation for the connection between a higher rate of OME and adenoid hypertrophy in children with coexisting allergic diseases may lay in the pathophysiology of allergy.

It is said that the inflammation mediators found in ear exudates from allergic patients are similar to those found in the late phase of an allergic response. Moreover, the mucosa found in middle ear emerges from the same ectoderm as the rest of the mucosa of the respiratory system [4]. This means the middle ear is capable of an allergic response and may be treated as a compartment of the "united airway" $[4,5]$. Summarizing, it behaves similarly to any other part of the respiratory tract in allergic patients, where the inflammatory response leads to swelling and obstruction [5].

OME is one of the most common conditions in the pediatric population, where non-purulent fluid is retained behind the tympanic membrane in the middle ear, causing conductive hearing loss. If such a condition persists, especially in younger children, this may lead to a delay in speech development [6]. OME might be called a silent disease, as it rarely presents visible symptoms, and due to this, it might be a challenge to diagnose. The symptoms vary depending on the child's age. This could be an impression of a full ear, tinnitus or autophony, but in younger children, the only sign of hearing impairment might be poor concentration or worsening of the child's behavior [7]. In Poland, the occurrence of temporary or permanent hearing loss of mild or moderate severity can be seen in $3.4 \%$ of children from primary school and $0.6 \%$ of middle school students [8]. The etiology of $\mathrm{OME}$ is multifactorial, and there are various factors influencing it, such as the male sex, craniofacial abnormalities, school attendance, exposure to tobacco smoke [9]. The allergy and its increased incidence in OME or adenoid hypertrophy remains disputed, and many studies are now being conducted to establish the relationship between these entities. 


\section{Objectives}

Establishing the prevalence of allergic diseases in children with adenoid hypertrophy with or without otitis media with effusion admitted to the Department of Pediatric Otolaryngology in Poznan between 05.2017 and 05.2018. Checking if allergy affects the incidence of OME or adenoid hypertrophy and verifying weather allergy influences the incidence of OME and adenoid hypertrophy.

\section{Material and methods}

\section{Study design, setting and participants}

This research was a cross-sectional study concerning children with adenoid hypertrophy or OME or both. The study was conducted at the Pediatric Otolaryngology Department in Poznan, Poland, between 05.2017 and 05.2018. Each patient admitted to the hospital for adenoidectomy or tympanostomy tube placement was carefully interviewed for any history of allergic diseases. Patients were assigned to the allergic patient group only if asthma, allergic rhinitis or atopy was diagnosed and treated by an Allergist and the patient had either positive skin or blood test results or a copy of his/her history with diagnoses and treatment. At admission, at full ENT examination by a physician was conducted, and a hearing test was performed. Each patient with OME was examined using a portable tympanometer, was carried out/performed depending on the patient's age or cooperation level.

The research was carried out in accordance with the ethical principles of scientific research, the Declaration of Helsinki, as well as the Ethical Code of the Polish Academy of Science.

\section{Statistical methods}

The results obtained were analyzed statistically. The chi-square test was used, with a $p$ value $<0.05$.

\section{Results}

153 patients aged 2 to 16 years (68 girls and 85 boys) were admitted to the Pozan Pediatric Otolaryngology Department between 05.2017 and 05.2018. 62 children applied for adenoidectomy with tympanostomy tube placement, 83 only for adenoidectomy and 8 only for tympanostomy tube placement. The children under study were in pre-school or school age, from 2 to 17 years old (Me $(Q 25-Q 75)=6(5-8))$. They were divided according to age into three subgroups: below 7 years $=$ preschool children, $n=87$ (37 girls, 50 boys); younger school children, aged 7 to 9 years, $n=52$ ( 28 girls, 24 boys), and elder school children, aged 9 to 17 years, $n=14$ ( 3 girls, 11 boys). No differences were found between the age groups concerning sex (chi-square test non-significant) (Table 1).

11 patients were referred only for an adenoidectomy, but the hearing test and the interview revealed hearing impairment, and they were eventually were diagnosed with otitis media with effusion and underwent tympanostomy tube placement.

8 patients were referred to tympanostomy tube placement with adenoidectomy but had good hearing test results upon admission, and in these patients, only an adenoidectomy was eventually performed. 25 patients had a history of allergic disease. From this group, 11 patients were referred to the hospital because of OME, and 14 only due to adenoid hypertrophy and frequent upper respiratory system infections. From these patients, 7 were female, and 18 were male (Figure 1).

Our data shows that $16.9 \%$ of children undergoing adenoidectomy and $17.4 \%$ of children undergoing adenoidectomy with tympanostomy tube placement suffered from allergic disease (Table 2, Figure 2).

\begin{tabular}{|c|c|c|c|c|}
\hline$\frac{\text { के }}{\frac{10}{0}}$ & & 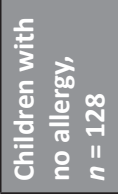 & 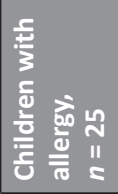 & 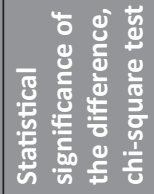 \\
\hline \multirow{2}{*}{$\begin{array}{l}\text { Right ear } \\
\text { pure tone } \\
\text { audiogram }\end{array}$} & correct & 37 & 9 & \multirow[t]{2}{*}{ ns } \\
\hline & incorrect & 16 & 5 & \\
\hline \multirow{2}{*}{$\begin{array}{l}\text { Left ear } \\
\text { pure tone } \\
\text { audiogram }\end{array}$} & correct & 33 & 7 & \multirow[t]{2}{*}{ ns } \\
\hline & incorrect & 18 & 6 & \\
\hline \multirow[t]{2}{*}{ Adenotomy } & yes & 123 & 22 & \multirow[t]{2}{*}{ ns } \\
\hline & no & 5 & 3 & \\
\hline \multirow{2}{*}{$\begin{array}{l}\text { Confirmed } \\
\text { OME } \\
\text { diagnosis }\end{array}$} & yes & 59 & 11 & \multirow[t]{2}{*}{ ns } \\
\hline & no & 69 & 14 & \\
\hline \multirow{2}{*}{$\begin{array}{l}\text { Ear tube } \\
\text { placement }\end{array}$} & yes & 59 & 11 & \multirow[t]{2}{*}{ ns } \\
\hline & no & 69 & 14 & \\
\hline \multirow{2}{*}{$\begin{array}{l}\text { Initial OME } \\
\text { diagnosis }\end{array}$} & yes & 65 & 14 & \multirow[t]{2}{*}{ ns } \\
\hline & no & 63 & 11 & \\
\hline
\end{tabular}

Table 2. Differences in investigated clinical parameters according to confirmed allergic conditions in the investigated children. The chi-square test was used, $p<0.05$

\begin{tabular}{|c|c|c|c|c|}
\hline 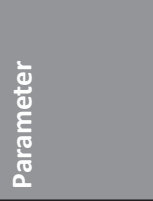 & & vi & $\begin{array}{ll}20 \\
0 \\
0 \\
0\end{array}$ & 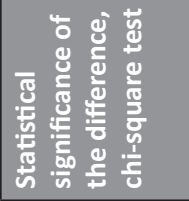 \\
\hline \multirow[t]{2}{*}{ Allergy } & yes & 7 & 18 & \multirow[t]{2}{*}{ ns } \\
\hline & no & 61 & 67 & \\
\hline \multirow{2}{*}{$\begin{array}{l}\text { Right ear } \\
\text { pure tone } \\
\text { audiometry }\end{array}$} & correct & 19 & 27 & \multirow[t]{2}{*}{ ns } \\
\hline & incorrect & 11 & 10 & \\
\hline \multirow{2}{*}{$\begin{array}{l}\text { Left ear } \\
\text { pure tone } \\
\text { audiometry }\end{array}$} & correct & 18 & 22 & \multirow[t]{2}{*}{ ns } \\
\hline & incorrect & 10 & 14 & \\
\hline \multirow[t]{2}{*}{ Adenotomy } & yes & 66 & 79 & \multirow[t]{2}{*}{ ns } \\
\hline & no & 2 & 6 & \\
\hline \multirow{2}{*}{$\begin{array}{l}\text { Confirmed } \\
\text { OME } \\
\text { diagnosis }\end{array}$} & yes & 24 & 46 & \multirow[t]{2}{*}{$5.39 ; p=0.020$} \\
\hline & no & 44 & 39 & \\
\hline \multirow{2}{*}{$\begin{array}{l}\text { Ear tube } \\
\text { placement }\end{array}$} & yes & 24 & 46 & \multirow[t]{2}{*}{$5.39 ; p=0.020$} \\
\hline & no & 44 & 39 & \\
\hline \multirow{2}{*}{$\begin{array}{l}\text { Initial OME } \\
\text { diagnosis }\end{array}$} & yes & 29 & 50 & \multirow[t]{2}{*}{$3.96 ; p=0.047$} \\
\hline & no & 39 & 35 & \\
\hline
\end{tabular}

From 62 patients with an initial diagnosis of OME, 30 had type $B$ tympanogram bilaterally, 6 had type $C$ tympanogram bilaterally, and 4 had type $A$ tympanogram bilaterally. 3 patients had type $C$ tympanogram in one ear and type $A$ in another, 5 patients had type $B$ tympanogram in one ear and $A$ in another, and 11 patients had type $B$ tympanogram in one ear and type $C$ tympanogram in another. 3 patients presented with their own hearing test results, and they were not eligible for this research (Figure 3). 

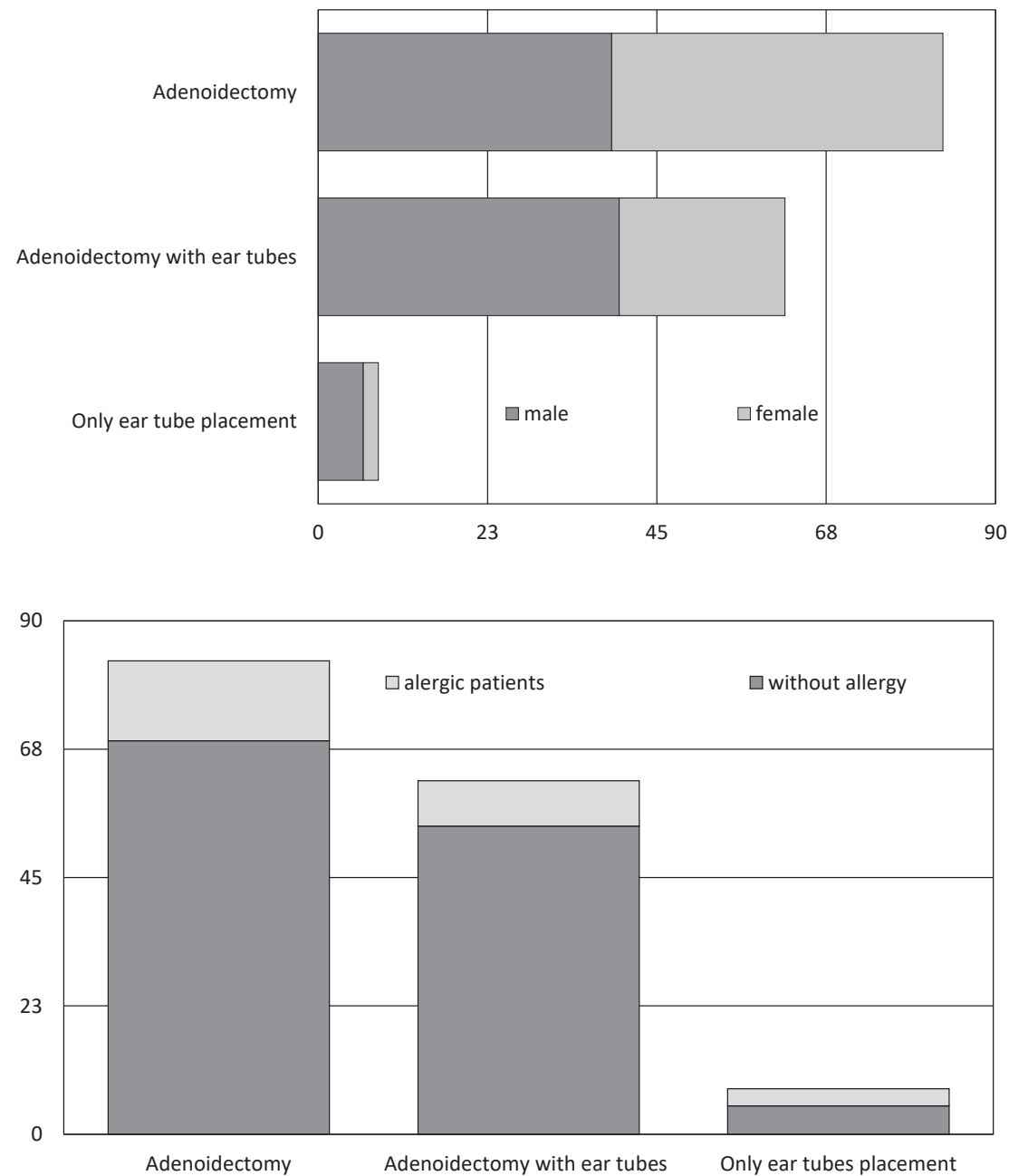

Figure 1. Children admitted for adenoidectomy with or without tympanostomy tube placement or only ear tube placement divided by sex
Figure 2. Allergic and non-allergic patients admitted for adenoidectomy with or without tympanostomy tube placement or only ear tube placement

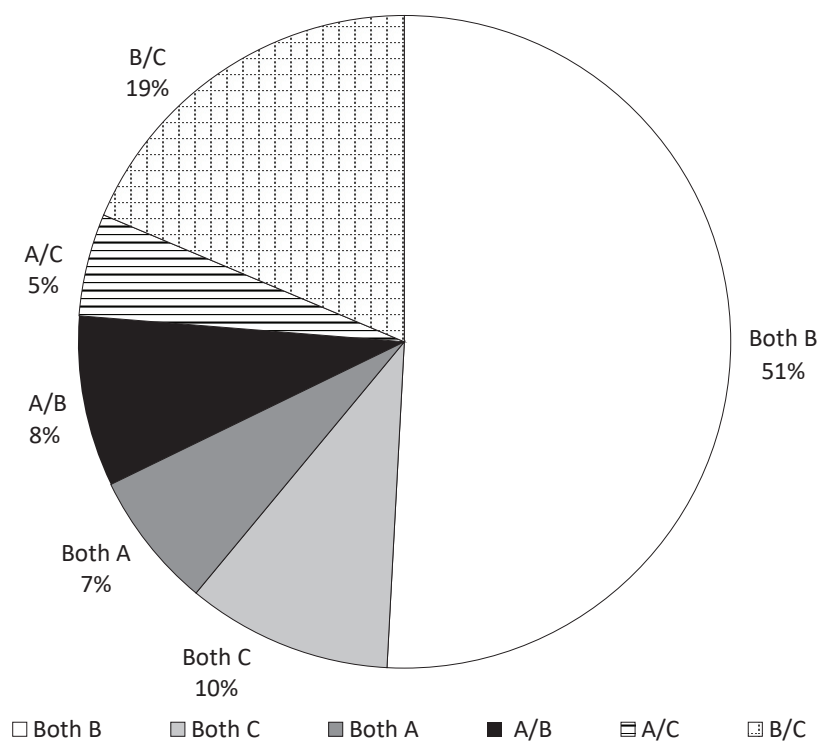

Figure 3. Diagram showing tympanometry results in children with otitis media with effusion and adenoid hypertrophy

\section{Discussion}

OME is defined as the accumulation of fluid behind the intact tympanic membrane, with no acute inflammation signs, leading to hearing impairment. Hearing deterioration, if persisting at a very young age, may eventually lead to a delay in speech development. OME is a very common condition in the pediatric population and a frequent cause of visits to the primary care unit. It is estimated that more than $50 \%$ of children in their first year of life will experience OME. Most of these children will recover spontaneously within 3 months and not require any medical treatment. However, in up to $10 \%$ of these children, the exudates will last for a year or even longer [10]. According to OME treatment guidelines, in such cases, ear grommet insertion is the only advised therapy [11]. Tympanostomy tubes are small canals inserted in the tympanic membrane that equalize middle ear pressure. However, in allergic patients or in those with an enlarged adenoid, ventilation tube insertion seems to be less effective than in non-allergic patients, and recurrences of OME are more often present [12].

There are many factors predisposing to OME, yet allergy is one of the most disputed. In many studies conducted over the last few years, the relationship between allergic diseases and increased susceptibility to OME was highlighted. Kwon et al. established that the incidence of OME is much higher in children with allergic rhinitis (31\%) than in the control group (16\%). They also stated that adenoid hypertrophy was greater in children with comorbid allergy [13].

Moreover, in Japan, Tomonaga et al. estimated that $50 \%$ of children with OME included in the study had allergic rhinitis, and $21 \%$ of patients with allergic rhinitis had OME [14].

The susceptibility to allergy seems to be even higher in Sicilian children. Martines et al. calculated that $62.9 \%$ of children with positive skin tests suffered from OME [15]. This finding might be very important when it comes to OME treatment: an adequately controlled inflammatory response with proper pharmacological therapy may result in exudate resolution [5]. In recently published guidelines for OME, Rosenfeld et al. permitted the use of topical intranasal steroid drops in OME treatment in patients with allergy, as they are said to reduce the inflammatory response in allergic patients [11]. 
According to Rosenfeld et al., pneumatic otoscopy is a basic diagnostic method for determining OME. In our Department, we tend to apply acoustic tympanometry in each patient as an alternative to pneumatic otoscopy. The tympanogram is a graphic version of the sound energy reflected back from the tympanic membrane, measured by a small microphone in the ear canal. This provides us with an objective view of the middle ear status. Basically, we can divide tympanometric curves into 3 main types: Type A - with a sharp peak - indicates that the possibility of exudate behind the tympanic membrane is low; Type $B$ - flat - suggests a high chance of fluid behind the tympanic membrane; and Type $\mathrm{C}$ - peak and negative ear pressure in the middle ear - shows an intermediate likelihood of encountering effusion [11]. Tympanometry is said to be as sensitive as pneumatic otoscopy; however, it is less specific [11]. In our study group from 62 patients admitted for adenoidectomy with tympanostomy tube placement, 30 (51\%) had type B tympanogram in both ears, so the sensitivity of this examination, in our case, was not satisfactory. To make the hearing test more reliable, we applied otoacoustic emission in children aged 1-5 and in patients who did not cooperate, and pure tone audiometry was applied in older children.

Our data seems to contradict studies conducted before and shows no correlation between allergy and the incidence of OME or adenoid hypertrophy. Unfortunately, these findings did not reach statistical significance and need further investigation. OME and ear tube placement were seen in boys more often than in girls, which was statistically significant. This finding is consistent with up-to-date literature [16]. Surprisingly, our findings show a lower percentage of children suffering from OME and allergy than the other studies mentioned above. In our study, $16.9 \%$ of children undergoing adenoidectomy and $17.4 \%$ of children undergoing adenoidectomy with tympanostomy tube placement suffered from allergic disease, which, in comparison with the
Japanese group (50\%) and Korean group (31\%), is significantly lower. However, the percentage of allergic children and adolescents in Poland ( $11 \%$ and $17 \%$, respectively) seems to be lower than in other countries. The National Health Interview Survey held in the US in 2014 revealed that $8.4 \%$ of children suffer from allergic rhinitis, $10 \%$ from respiratory allergies, 5.4\% from food allergies and $11.6 \%$ from skin allergies. This means that more than $30 \%$ of American children suffer from allergy [17]. Unfortunately, an increasing trend for allergic diseases amongst US children, especially respiratory allergy, has been noticed over the last few years [18]. The same growing trend is visible amongst Polish children [19]. Further studies are planned to confirm the allergy rate amongst patients with OME and adenoid hypertrophy. Perhaps the prevalence of allergy will change in time as the tendency for allergic diseases grows in general.

\section{Limitations of the study}

The study was conducted in one pediatric tertiary center, and the authors are aware of this limitation. However, in the future, further studies to collect data concerning allergy in patients with OME and adenoid hypertrophy from other pediatric units are planned.

\section{Conclusions}

Although it is said allergic diseases influence the incidence of OME and adenoid hypertrophy in children, our study did not reveal such a finding. Allergy seemed not to affect the incidence of OME or adenoid hypertrophy in our study group. The only statistically significant result is the higher incidence of OME and adenoid hypertrophy in boys. The prevalence of allergy in patients with OME or adenoid hypertrophy in our study seems to be lower than in other studies conducted previously.

Source of funding: This work was funded by the authors' own resources.

Conflict of interest: The authors declare no conflict of interests.

\section{References}

1. Szymborski J, ed. Zdrowie dzieci i młodzieży w Polsce. Zarys diagnozy i kierunków poprawy. Warszawa: Wydawnictwo Rządowa Rada Ludnościowa; 2012 (in Polish).

2. Hellings PW, Fokkens WJ. Allergic rhinitis and its impact on otorhinolaryngology. Allergy 2006; 61: 656-664 (Review).

3. Sadeghi-Shabestari M, Jabbari Moghaddam Y, Ghaharri H. Is there any correlation between allergy and adenotonsillar tissue hypertrophy? Int J Pediatr Otorhinolaryngol 2011; 75: 589-591.

4. Yang B, Brook CD. The role of allergy in otologic disease. Otolaryngol Clin North Am 2017; 50(6): 1091-1101.

5. Nguyen LHP, Manoukian JJ, Sobol SE, et al. Similar allergic inflammation in the middle ear and the upper airway: evidence linking otitis media with effusion to the united airways concept. J Allergy Clin Immunol 2004; 114: 1110-1115.

6. Teele DW, Klein JO, Rosner B. Otitis media with effusion during the first three years of life and the development of speech and language. Pediatrics 1984; 74: 282-286.

7. Gravel JS, Wallace IF. Effects of otitis media with effusion on hearing in the first 3 years of life. J Speech Lang Hear Res 2000; 43(3): 631-644.

8. Kocka K, Ślusarska B, Bartoszek A, et al. Comparative analysis of health problems in students from elementary school and middle school in Lublin 2010-2015. Fam Med Prim Care Rev 2018; 20(1): 7-12.

9. Zernotti ME, Pawankar R, Ansotegui I, et al. Otitis media with effusion and atopy: is there a causal relationship? World Allergy Organ J 2017; 10(1), doi: 10.1186/s40413-017-0168-x.

10. Martines F, Bentivegna D. Audiological investigation of otitis media in children with atopy. Curr Allergy Asthma Rep 2011; 11(6): 513-520 .

11. Rosenfeld RM, Shin JJ, Schwartz SR, et al. Clinical practice guideline: otitis media with effusion (update). Otolaryngol Head Neck Surg 2016; 154 (1 Suppl.): S1-S41, doi: 10.1177/0194599815623467.

12. Zhang Y, Xu M, Zhang J, et al. Risk factors for chronic and recurrent otitis media - a meta-analysis. PLoS ONE 2014; 9(1): e86397, doi: 10.1371/journal.pone.0086397.

13. Kwon C, Lee HY, Kim MG, et al. Allergic diseases in children with otitis media with effusion. Int J Pediatr Otorhinolaryngol 2013; 77(2): 158-161.

14. Tomonaga K, Kurono Y, Mogi G. The role of nasal allergy in otitis media with effusion: a clinical study. Acta Oto-Laryngologica 1998; 105(Suppl. 458): 41-47.

15. Martines F, Bentivegna D, Piazza FD, et al. The point prevalence of otitis media with effusion among primary school children in Western Sicily. Eur Arch Otorhinolaryngol 2010; 267: 709-714, doi: 10.1007/s00405-009-1131-4.

16. Eliçora S, Ş Öztürk M, Sevinç R, et al. Risk factors for otitis media effusion in children who have adenoid hypertrophia. Int J Pediatr Otorhinolaryngol 2015; 79(3): 374-377. 
17. American College of Asthma, Allergy and Immunology. Allergy facts. 2017 Apr. [cited 14.05.2018]. Available from URL: http://www. acaai.org/news/facts-statistics/allergies.

18. Jackson KD, Howie LD, Akinbami LJ. Trends in allergic conditions among children: United States, 1997-2011. NCHS Data Brief 2013; 121: 1-8.

19. Samoliński B, Raciborski F, Lipiec A, et al. Epidemiology of allergic diseases in Poland. Pol J Allergol 2014; 1: $10-18$.

Tables: 2

Figures: 3

References: 19

Received: 27.05.2018

Reviewed: 01.06.2018

Accepted: 25.07.2018

Address for correspondence:

Paulina Adamczyk, MD

Klinika Otolaryngologii Dziecięcej

Katedra Otolaryngologii i Onkologii Laryngologicznej UM

ul. Szpitalna 27/33

60-572 Poznań

Polska

Tel.: +48 61 849-15-90

E-mail: paulina.adamczyk89@gmail.com 